Vernia Carrasco, Ana Mercedes.

Universidad Jaume I de Castellón, profesora investigadora Departamento de Educación

Didáctica de la Expresión Musical.

\title{
La producción artística en el ámbito educativo. El proyecto escénico como herramienta de aprendizaje.
}

\section{Artistic production in the educational field. The scenic project as a tool for learning.}

\author{
TIPO DE TRABAJO: \\ Comunicación. \\ PALABRAS CLAVE: \\ Expresión corporal, Dalcroze, Formación, Maestro de primaria. \\ KEY WORDS: \\ Body Expression, Dalcroze, Formation, Primary School Teacher.
}

\section{RESUMEN.}

Podemos entender la producción artística dentro del terreno profesional y como parte del currículum en determinadas formaciones. Nuestra propuesta parte de un proyecto escénico como herramienta de aprendizaje en el grado de maestro de educación primaria y cómo la gestión de dicho proyecto puede repercutir en diferentes competencias transversales, que ayuden a mejorar el rendimiento del alumnado e incremente sus conocimientos relacionados con la materia de Didáctica de la Expresión Musical, llegando a conectarse con la realidad, para que la formación pueda ser útil no sólo desde las competencias específicas del Currículum.

\begin{abstract}
La visión respecto de la producción artística está muy vinculada a la gestión cultural, en cambio, podemos entender que la gestión no sólo debe pasar por temas económicos, sino que debe incidir en el terreno social, educativo, y de sostenibilidad. Los maestros de educación musical suelen hacer sus propias producciones artísticas, sin haber disfrutado a lo largo de su formación de meros conocimientos que implica la profesión, reduciéndose al final a un simple espectáculo de aula, que en el mejor de los casos ven los familiares y amigos del propio alumnado.
\end{abstract}

Nuestro primer paso ha sido averiguar, a través del futuro maestro de primaria, si un proyecto escénico podría ayudar a un aprendizaje significativo, fuera y dentro del aula. Nuestro segundo paso sería, cómo este alumnado de tercero en grado de primaria puede ser productor de su propio proyecto y qué competencias puede desarrollar.

ABSTRACT.

We can understand the artistic production within the professional field and as part of the curriculum in certain formations. Our proposal starts from a scenic project as a learning tool in the elementary school teacher's degree and how the management of this project can have repercussions on different transversal competences, that help to improve the student's performance and increase their knowledge related to the subject of Didactics of Musical Expression, coming to connect with reality, so that training can be useful not only from the specific competencies of the Curriculum. The vision regarding artistic production is closely linked to cultural management. Instead, we can understand that management must not only go through economic issues, but must also have an impact on social, educational, and sustainability. Music 
education teachers often make their own artistic productions, without having enjoyed along their formation of mere knowledge that involves the profession, reducing in the end to a simple classroom show, which in the best of cases see the family and Friends of the student body.

Our first step has been to find out, through the prospective elementary teacher, whether a stage project could help meaningful learning, outside and within the classroom. Our second step would be, how these third step students in elementary school can be the producer of their own project and what competencies can develop.

\section{CONTENIDO.}

\section{Introducción.}

La educación musical en Primaria tiene el objetivo de introducir al alumnado en el mundo artístico, potenciando además del espíritu crítico y la motivación e incidiendo en competencias básicas a través de la música, pero también atendiendo a contenidos o competencias específicas como la escucha, la interpretación y la creación musical.

Según Prieto (2001) el maestro de primaria especialista en Música, debería tener ciertas características entre las que cabe destacar las capacidades personales tanto las facultades emotivas o imaginativas, incidiendo en las capacidades de comunicación y de socialización. En cuanto a las capacidades musicales, este autor resalta la audición, reconocimiento, reproducción y representación de combinaciones sonoras y estructuras musicales sencillas, destacando el desarrollo del oído como fundamental para la correcta afinación, el canto y también la interpretación musical, sin olvidar la importancia de las habilidades psicomotoras, es decir, el cuerpo como herramienta de aprendizaje.

Respecto al profesorado generalista, en opinión de Serrano et al. (2007), no ha habido un interés por investigar la conveniencia o no del maestro especialista, aunque los posicionamientos está por una parte en que el maestro generalista atiende a que la educación es una sola cosa y el niño un todo único, por otra parte, el maestro especialista responde a que no todos los saberes de las diferentes materias pueden estar en posesión de una sola persona, no obstante la decisión para optar por uno u otro perfil, debiera evaluarse principalmente por su contribución a la educación de los niños. Añaden estos autores que hay diversos estudios que apuntan que los alumnos enseñados por maestros especialistas suelen obtener mejores resultados de aprendizaje. Estos autores afirman que la mayoría de los países europeos no son exclusivamente generalistas o especialista, pudiendo convivir perfectamente, según materias (educación física, música, artes e idiomas).

La Educación Musical siempre ha estado vinculado al desarrollo de la persona, ya desde la Grecia Clásica se consideraba a la Música como un elemento relevante dentro de la Educación. Hoy, en el siglo XXI, la Educación Musical es un derecho del ser Humano, por ello su enseñanza no se debe relegar a una minoría privilegiada, sino que debe incluirse en el Currículum oficial, así como dentro del ámbito de la Educación y Formación de las personas adultas.

Haber adquirido conocimientos no significa ser competente, pues se pueden conocer diferentes técnicas y no necesariamente saberlas aplicar (Parcerisa, 2007). En opinión de este autor, cada etapa educativa debería definir sus competencias, definiendo los objetivos desde cada área o asignatura, en forma de capacidades que permitan avanzar hacia las competencias.

- Las competencias especificas o transversales deben ser el referente para definir los objetivos de cada área o asignatura.

- Para la adquirir competencias se han de conseguir recursos y aprendizaje para movilizarlos.

- Los contenidos deben relacionarse con los objetivos a los que responden.

- Para la enseñanza por competencias es fundamental la coordinación entre docentes.

Ilustración 1: Competencia docente. Fuente: Parcerisa (2007) 
Ante la situación respecto al actual perfil del futuro maestro de primaria, era necesario buscar estrategias y herramientas que permitieran un aprendizaje global y significativo para las aulas del siglo XXI y así surgió el "Proyecto Escénico".

\section{Desarrollo.}

Este proyecto se basa en la formación musical del futuro. Cambiar el papel del futuro docente de música y situarlo como alumnado que muestra su aprendizaje a quienes serán sus futuros alumnos. El alumnado constató la adquisición de competencias teórico prácticas musicales, herramientas didácticas y pedagógicas, así como el conocimiento y observancia de las normas de comportamiento en audiciones y otras representaciones musicales, además de la confianza en las propias posibilidades de producción musical y valoración de la estética expresiva del movimiento. La Metodología desarrollada se basó en la participación del trabajo en grupo, el consenso, la cooperación y colaboración, dirigidos a potenciar diferentes conceptos didácticos, que deben ser significativos para su aprendizaje, pero sobre todo para su enseñanza, preparándose, para el mundo real, desde la resolución de problemas y cómo esto puede suponer un impacto social. Los beneficiarios de este tipo de proyecto son todos los participantes, tanto desde el público como desde el escenario, convirtiéndose en actores activos de su propio rol. Como emisores y receptores, pueden disfrutar aprendiendo a aprender.

El impacto social que la música y los espectáculos musicales ejerce en la ciudadanía, se constata en diferentes proyectos, tales como:

- Los proyectos que se están llevando a cabo en los diferentes Auditorios de Música, sólo hay que comprobar sus programaciones didácticas, como en el auditorio ${ }^{1}$ de Tenerife, el proyecto de la orquesta de Euskadi ${ }^{2}$ o el auditorio de Castellón ${ }^{3}$, entre otros.

La preparación para el desarrollo de un proyecto musical con impacto social debe adquirirse desde todas las facetas posibles, en la formación que el futuro docente recibe, porque de ellos depende una Educación de Calidad, la cual pasa, indiscutiblemente, por la educación musical.

El proyecto escénico consta de una serie de canciones, escogidas por el estudiantado o creadas por ellos y dirigidas a un determinado nivel de primaria, a través de las cuales se trabajan contenidos teóricos musicales utilizando únicamente la expresión rítmica y corporal. Así, con la elaboración de esta propuesta, el estudiantado ha adquirido herramientas para aplicar a la docencia, mejorando y ampliando su bagaje teórico práctico musical. El espectáculo, dirigido especialmente al alumnado de primaria, se ofreció dentro de la programación didáctica del Auditorio de Castellón. De este modo, se pretende acercar el alumnado a sus futuros maestros para que observe cómo muestra sus conocimientos de una manera lúdica y motivadora. Por otro lado, el futuro profesorado también tiene la oportunidad de acercarse en los espacios artísticos implicándose en el esfuerzo que supone no sólo estar en un escenario sino conseguir un buen funcionamiento de un espectáculo didáctico. Además, se contribuye desde la Universidad a que los auditorios sean un espacio más de la educación integra para todas las edades, potenciando el aprecio por las artes.

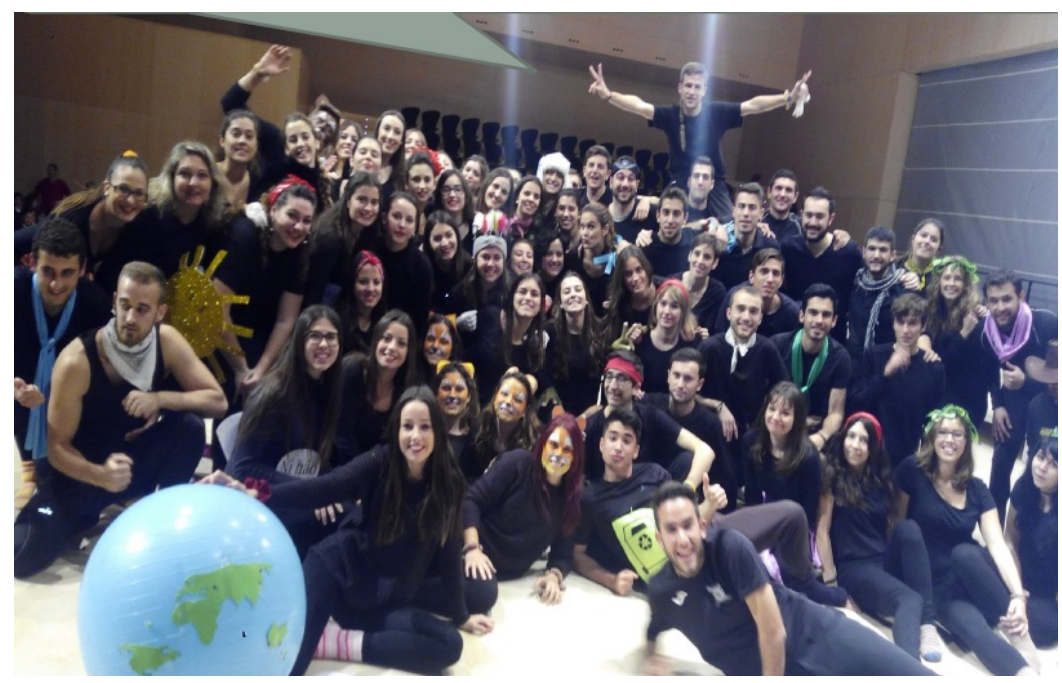

Ilustración 2: Alumnado participante en el Proyecto escénico. Fuente: Elaboración propia

\footnotetext{
${ }^{1} \mathrm{http}: / /$ auditoriodetenerife.com/proyecto/area-educativa/

2 http://www.euskadikoorkestra.es/es/aula centros.asp

${ }^{3} \mathrm{http}: / / \mathrm{www}$.culturalcas.com/es/didactica/
} 
Todo el trabajo corporal se basa en la pedagogía de J. Dalcroze, pedagogo que partía de que las primeras experiencias de aprendizaje son de origen motriz y el ritmo musical solamente puede adquirirse a través de una implicación global. Así, la educación rítmica se podrá desarrollar mediante marchas o movimientos corporales, estableciéndose el cuerpo como el intermediario entre sonido y pensamiento (Conde, Martín y Viciana, 2004). En opinión de Dalcroze, la sensibilidad nerviosa (sensibilité nerveuse) permite reconocer y experimentar todos los matices cualitativos de la actividad motriz, estableciendo conexiones entre las ideas artísticas y musculares. Por ello, Dalcroze dice que el objetivo de la plástica animada es conseguir el equilibrio entre las acciones corporales, permitiendo sentir y expresar la música corporalmente. No se trata propiamente de una coreografía sino más bien de expresar o interpretar una música a través del cuerpo (Juntunen, 2004).

Si el aprendizaje musical puede hacer aportaciones al movimiento y a la danza, el referente más claro lo podemos hallar en Dalcroze, quien a través de su método fundamentado en el ritmo y el movimiento se convirtió en uno de los principales innovadores que influyeron en la danza moderna. Sus investigaciones se dirigieron a combatir la arritmia, cuya causa, según él, es debida a la falta de armonía en los factores intelectuales. Su método se fundamenta en la asimilación de los ritmos mediante la repetición, el encadenamiento lógico de causa y efecto, en el que la música es la causa y el efecto sería el movimiento junto con la acción expresiva y la economía corporal en la que el ritmo musical ordena al ritmo interior, siendo sus principales puntos de estudio en la danza la respiración y la orquestación de los movimientos (Markessinis, 1995), elementos estos últimos característicos de la música.

El autor anterior enumera las siguientes reglas de conjunción cuerpo/mente según el método de Dalcroze:

Establecer una comunicación rápida entre cerebro y cuerpo.

Crear automatismos que aseguren el funcionamiento muscular. Toma de conciencia de nuestra personalidad.

Aprender a relajarse para que el cuerpo se disponga a recibir órdenes del cerebro.

Máximo resultado con el mínimo esfuerzo, creando costumbres motrices y reflejos.

Canalizar las fuerzas vivas del ser humano para llevar una vida ordenada, inteligente e independiente.

Los recursos materiales, en proyectos audiovisuales, son fundamentales para poder ofrecer calidad, en cambio sólo se dispuso de un ordenador con cortes de canciones, seleccionadas por el alumnado y una cámara digital de uso doméstico, para poder registra los trabajos.

\section{Conclusiones.}

Entre las conclusiones a las que hemos llegado, cabe destacar, por una parte, la valoración positiva en cuanto a aprendizaje de la didáctica de la música, sus elementos teóricos desde la práctica e implicación del alumnado en la elaboración de su propio proyecto, así como la dificultad que supone el trabajo en grupo para coordinar y programar las diferentes sesiones. Por otra parte, la necesidad en el aprendizaje de recursos audiovisuales y de producción artística para poder llegar a cabo proyectos-educativos que impliquen la puesta en escena desde elementos audiovisuales, como este caso, entre los que pensamos incluir la gestión y márquetin, pues bajo nuestro punto de vista, el maestro debe ser competente en este terreno, ya que actualmente apreciamos una escuela viva, activa y participativa del arte y la cultura y no debemos perder la calidad en los proyectos, sólo por tratarse de un nivel educativo básico.

Entendemos, que el proyecto escénico resulta muy motivador, aunque la primera reacción es de rechazo, pues asocian el movimiento ya la expresión corporal al baile puramente, durante el proceso de elaboración se pueden percibir cambios actitudinales en los estudiantes, manifestando tanto el crecimiento del interés en esta actividad como la significatividad de la misma para la adquisición de contenidos teórico musicales como las figuraciones rítmicas, tempo, compás o fraseo.

Por otra parte, debemos señalar, que la escasez de recursos materiales no desmotivó al alumnado, a pesar que hubo alguna pequeña incidencia en la reproducción del sonido desde el ordenador, lo que incitó al alumnado a ser creativo y actuar de manera improvisada hasta poder solucionar la incidencia. Así, debemos señalar las necesidades requeridas para desarrollar el proyecto no sólo con la calidad que muestren los participantes sino también con la necesaria calidad de registro y reproducción del resultado final. 


\section{FUENTES REFERENCIALES.}

Conde, J., Martín, C., y Viciana, V. (2004). Las canciones motrices: Metodología para el desarrollo de las habilidades motrices en educación infantil y primaria a través de la música. (3ae ed.). Barcelona: Inde.

Juntunen, M.L. (2004). Embodiment in Dalcroze Eurhythmics. Oulu: Oulu University Press.

Markessinis, A. (1995). Historia de la danza desde sus orígenes. Madrid: Librería deportiva ESM.

Parcerisa, A. (2007). Las competencias como referentes para la práctica educativa. Eufonía: Didáctica de la música, 41, 6-16.

Prieto, R. (2001). El Perfil del Maestro de Primaria Especialista en Educación Musical.

Revista Interuniversitaria de Formación del Profesorado.

Serrano, J.A., Lera, A. y Contreras, O. (2007). Maestros generalistas vs especialistas. Claves y discrepancias en la reforma de la formación inicial de los maestros de primaria. Revista de Educación, 344. Septiembre-diciembre 2007, pp. 533-555 